\title{
Beliefs and Attitudes Associated With the Intention to Not Accept the Diagnosis of Depression Among Young Adults
}

Benjamin W. Van Voorbees, MD, $M P H^{1}$

Josbua Fogel, $\mathrm{PbD}^{2}$

Thomas K. Houston, MD, MPH

Lisa A. Cooper, $M D, M P H^{4-6}$

Nae-Yub Wang, $P b D^{4}$

Daniel E. Ford, $M D, M P H^{4-7}$

'Departments of Medicine and Pediatrics, The University of Chicago, Chicago, Ill

${ }^{2}$ Business Program, Department of Economics, Brooklyn College of the City University of New York, Brooklyn, NY

${ }^{3}$ Department of Medicine and the Center for Outcomes and Effectiveness Research and Education, University of Alabama School of Medicine, Birmingham, Ala

${ }^{4}$ Department of Medicine, Johns Hopkins University School of Medicine, Baltimore, Md

${ }^{5}$ Welch Center for Prevention, Epidemiology, and Clinical Research, Baltimore, Md

${ }^{6}$ Department of Health Policy and Management, Johns Hopkins Bloomberg School of Public Health, Baltimore, Md

${ }^{7}$ Department of Psychiatry and Behavioral Sciences, Johns Hopkins School of Medicine, Baltimore, Md

Conflicts of interest: none reported

\section{CORRESPONDING AUTHOR}

Benjamin W. Van Voorhees, MD, MPH Section of General Internal Medicine The University of Chicago

5841 South Maryland Avenue, MC 20007

Chicago, IL 60637

bvanvoor@medicine.bsd.uchicago.edu

\begin{abstract}
PURPOSE Negative attitudes and beliefs about depression treatment may prevent many young adults from accepting a diagnosis and treatment for depression. We undertook a study to determine the association between depressive symptom severity, beliefs about and attitudes toward treatment, subjective social norms, and past behavior on the intent not to accept a physician's diagnosis of depression.
\end{abstract}

METHODS We conducted a cross-sectional study of 10,962 persons aged 16 to 29 years who participated and had positive screening results on the Center for Epidemiologic Studies Depression (CES-D) score in an Internet-based public health depression screening program. Participants reported whether they would accept their physician's diagnosis of depression. Based on the theory of reasoned action, we developed a multivariate model of the factors that predict intent not to accept a diagnosis of depression.

RESULTS Twenty-six percent of the participants stated their intent not to accept their physician's diagnosis of depression. Disagreeing that medications are effective in treating depression (strongly disagree, odds ratio (OR ) $=6.5,95 \%$ confidence interval $(\mathrm{Cl}), 4.6-9.3)$, that there is a biological cause for depression (strongly disagree, $\mathrm{OR}=1.9,95 \% \mathrm{Cl}, 1.3-2.7$ ), and agreeing that you would be embarrassed if your friends knew you had depression were associated with the intent not to accept a diagnosis of depression (strongly agree, OR $=2.3,95 \%$ $\mathrm{Cl}, 1.8-2.9)$. Beliefs and attitudes, subjective social norms, and past behavior explained most of the variance in this model (84\%).

CONCLUSIONS Negative beliefs and attitudes, subjective social norms, and lack of past helpful treatment experiences are associated with the intent to not accept the diagnosis of depression and may contribute to low rates of treatment among young adults.

Ann Fam Med 2005;3:38-45. DOI: 10.1370/afm.273.

\section{INTRODUCTION}

T

wenty-five percent of young adults will experience a depressive episode by age 24 years, the highest incidence rate of any adult agegroup. ${ }^{1-3}$ Although depression during this critical period may increase the likelihood of substance abuse, impair work and relationship function, and negatively influence an individual's subsequent development, ${ }^{1,4-11}$ fewer than $20 \%$ of young adults with depression receive high-quality care. ${ }^{12}$

Lack of health insurance coverage and affiliation with a primary care physician do not fully explain these low treatment rates. ${ }^{13,14}$ Obtaining treatment for depression is a multistage process that includes self-evaluation of need for care, seeking services, and finally accepting a diagnosis and treatment for the disorder, which is substantially influenced by patient attitudes. ${ }^{15,16}$ Patient reluctance to accept diagnosis and treatment for depression has been identified by primary care physicians as a major barrier to implementing 
evidence-based treatment for depression ${ }^{17}$ and may be associated with poor quality of care and outcomes. ${ }^{18-24}$ Why patients refuse the diagnosis and treatment for depression remains poorly understood, however.

The theory of reasoned action, which has been used to predict a variety of health behaviors, provides a theoretical framework for understanding why many patients will not accept their physician's diagnosis of depression. ${ }^{25-27}$ According to the theory of reasoned action, intention is the critical determinant of behavior. Intention is determined by beliefs and attitudes about treatment behaviors (eg, medication efficacy and adverse effects), subjective social norms (eg, concern with regard to family opinions), past behavior (eg, past treatment), perceived behavioral control (eg, theory of planned behavior), and self-efficacy. ${ }^{28}$ The balance of favorable and unfavorable attitudes, subjective social norms, beliefs about control and self-efficacy, and past behavior will determine intention, which in turn leads to action. ${ }^{28,29}$ Intentions measured close to the actual behavior (in both time and place) strongly predict action. ${ }^{29}$

Internet surveys are a cost-effective way to obtain information from non-clinic-based populations, such as those who may be seeking or considering care but are not yet in treatment. ${ }^{30,31}$ Seventy-five percent to $80 \%$ of adolescents and young adults have Internet access and use the Internet to search for health information, usually in the early stages of care seeking (ie, considering seeking or accepting treatment). ${ }^{32-35}$ In this study, using results from an Internet survey of 10,962 young adults, we developed a multivariate model of intent to not accept a diagnosis of depression, based on the theory of reasoned action as revised by Howland and Hagger $^{27,28}$ (Figure 1). As we measured intention using the Internet in circumstances separate from possible action, we use the term intent to describe our outcome variable.

\section{METHODS}

\section{Study Design}

This study is a cross-sectional analysis of 10,962 young adults who completed an Internet-based screening test for depression between March 1999 and March 2000 on a major online health portal (Intelihealth [www.intelihealth.com], owned by US Aetna/Healthcare). Based on Zip codes, this database was subsequently cross-referenced with census information. To better understand the comparability of this sample to patients seen in primary care, we compared those of the Internet sample with those of a primary care sample of young adults (the Quality Improvement in Depression Study[ QID]).36,37

Internet users could access the Web site directly at http://www.Intelihealth.com/depressiontest, or by entering "depression test" into any search engine or through multiple direct links from other organizations. ${ }^{38}$ The Web site invited participants to "take a depression assessment" and provided participants with an assessment of their likelihood of having major depression based on their Center for Epidemiologic Studies Depression (CES-D) score: $<16$, low; 17 to 22 , moderate; and $>22$, high probability. ${ }^{39,40}$ In population screening, the CES-D cutoff score of 16 has sensitivity ranges of $86 \%$ to $100 \%$ and

\section{Figure 1. Theory of reasoned action and intention not to accept the diagnosis of depression.}

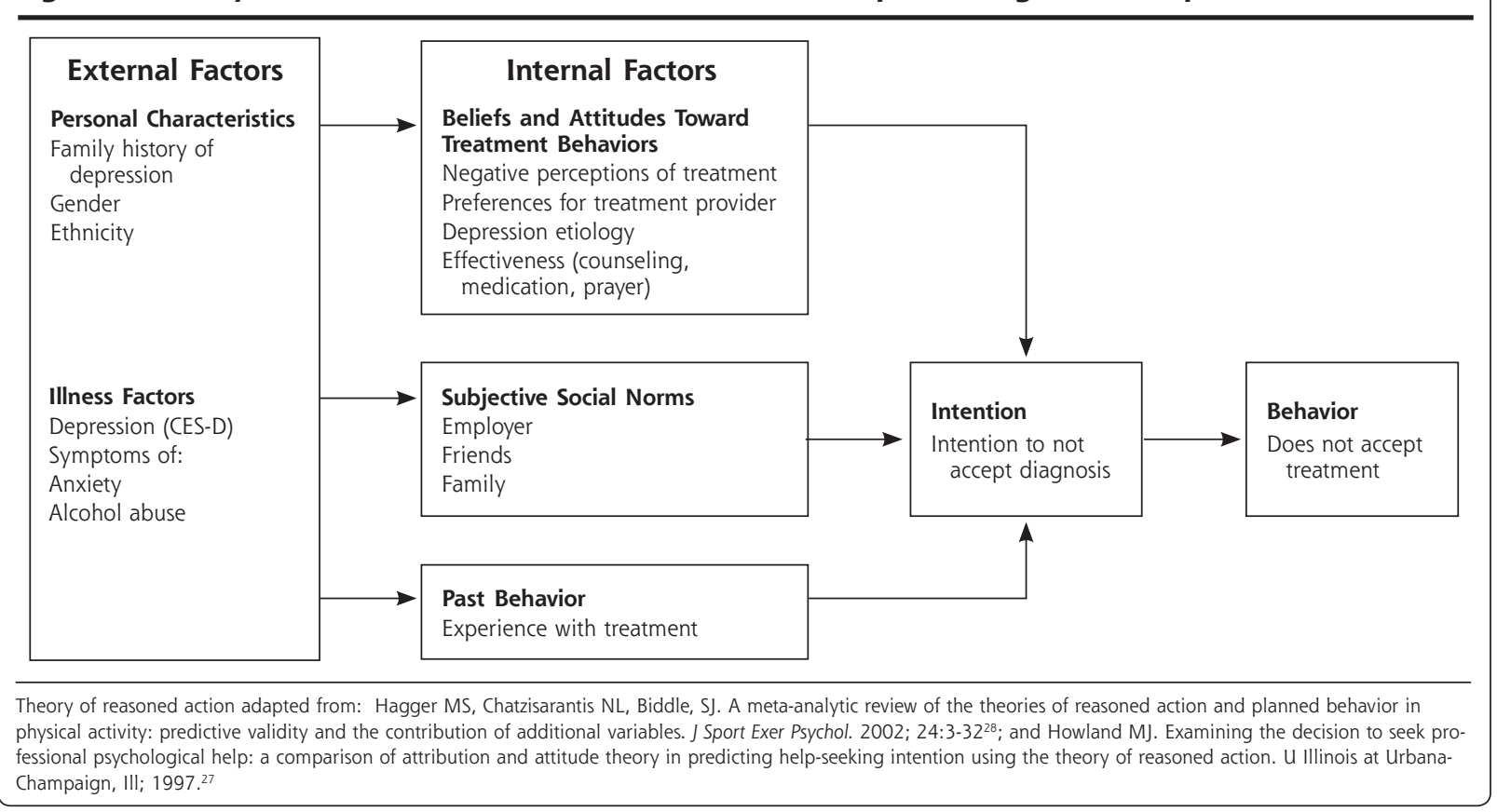

ANNALS OF FAMILY MEDICINE + WWW.ANNFAMMED.ORG + VOL. 3, NO. 1 + JANUARY/FEBRUARY 2005 
specificity ranges of $53 \%$ to $84 \% .^{38,39,41-45}$ Previous work describes the development of this Internet screening test and the selection of cutoff values for the CES-D scores. ${ }^{38}$

The Web site asked participants to complete a questionnaire concerning their beliefs and attitudes. Also, the Web site provided feedback similar to advice that is often provided after completing a depression screening questionnaire. Participants with a moderate or high probability of having depression were advised to "see a health professional to confirm the diagnosis and discuss what treatment might be best" and that "a delay in treatment could be dangerous." Participants were also cautioned that having positive screening results for depression was not equivalent to a diagnosis of depression ("about one quarter of individuals who score high are found not to have depression"). ${ }^{43}$ The Web site also sought to dispel common concerns about treatment.

\section{Study Population and Eligibility}

We included only those participants with a moderate or greater likelihood of having major depression (CES-D score $>16$ ). We excluded those who either reported the diagnosis of bipolar disorder (mania), symptoms consistent with this diagnosis, or treatment with lithium $(n=329)$. We did not, however, exclude individuals with symptoms in the last 4 weeks suggestive of other common mental disorders that often co-occur with depression (ie, generalized anxiety disorder, panic disorder, and alcohol abuse). ${ }^{1,8}$ No personal identification information was collected. The Johns Hopkins University School of Medicine Institutional Review Board approved this study.

\section{Dependent Variable}

The main outcome variable, "intent not to accept a diagnosis of depression," was constructed from the response to the question: "If my doctor told me I had depression, I could accept that." The participants responded with their level of agreement using a Likertstyle scale consisting of strongly agree, agree, neither agree nor disagree, disagree, and strongly disagree. We created a dichotomous variable. All participants who disagreed, strongly disagreed, or neither agreed nor disagreed were considered to have the intent not to accept a diagnosis of depression. We included those who neither agreed nor disagreed as having intent to not accept a depression diagnosis because attitude theory suggests that such individuals would be unlikely to take action and accept treatment. ${ }^{46}$ All those who agreed or strongly agreed were considered to have the intent to accept a diagnosis of depression. Intent not to accept a diagnosis of depression was strongly associated with having had no mental health services visits and not having received treatment with antidepressant medication in the previous 6 months (odds ratio $[\mathrm{OR}]=4.5$,
95\% confidence interval $[\mathrm{CI}], 1.4-15.0$, vs $\mathrm{OR}=1.0$ for intent to accept the diagnosis of depression) in the baseline survey of the comparison primary care sample.

\section{Independent Variables (Internal Factors)}

Beliefs and Attitudes, Social Norms

The beliefs and attitudes towards treatment behaviors ("beliefs and attitudes") and subjective social norm ("social norms") items used in this study were developed using focus group methods and were adapted post hoc to the theory of reasoned action model. ${ }^{36,47,48}$ Participants rated their agreement with several beliefs and attitudes, and social norm statements, using the same Likert scale used for the dependent variable. We constructed indicator variables for responses on the Likert scale for beliefs and attitudes: "biological changes in the brain cause depression," "some medications are effective in treating depression," "counseling is as effective as medication," "prayer can heal depression," "medications are addictive," "counseling brings up bad feelings," "prefer same gender provider," and "prefer same race provider," and social norms with regard to treatment: "my employer should not know," "I would be embarrassed if my friends knew," and "my family would be disappointed." Similarly, we created indicator references for treatment type: counseling, medication, or neither. Treatment options were defined for the preference item as "antidepressant medication for 6 to 9 months" or "counseling weekly for 3 months."

\section{Past Treatment Behavior (Past Behavior)}

We constructed indicator variables to describe each type of possible treatment experience in terms of form of treatment (medication or counseling) and whether each form of treatment was helpful. We used the available responses from 4 separate items of "ever taken medication for depression," "ever had counseling for depression," "how helpful was medication," and "how helpful was counseling." From these responses, we constructed the following mutually exclusive categories to describe type of treatment (whether the participant had experienced medication or counseling or both) and helpfulness of each treatment: (1) no past treatment, (2) both treatments not helpful, (3) medication helpful, (4) medication not helpful, (5) counseling helpful, (6) counseling not helpful, (7) medications helpful/counseling not helpful, and (8) counseling helpful/medications not helpful, and (9) both treatments helpful. Helpfulness was rated as not at all, not very, somewhat, and very. All responses of somewhat or very were characterized as helpful in the construction of the indicator variables. Participants who reported only 1 form of treatment were classified in either the medication or counseling groups, while those who had experienced both forms 
of treatment were placed in a combination group. For example, a participant who reported that medication treatment was helpful, but counseling was not, would be classified "medication helpful/ counseling not helpful," but not in the "medication helpful" or "counseling not helpful groups."

\section{Covariates (External Factors)}

\section{Personal Characteristics}

The model included sex, ethnicity, and family history of depression. With regard to family history, participants were asked whether "their mother, father, sisters, or brother previously had depression that lasted more than 4 weeks or had been treated for it." Our chosen young adult age range (ages 16 to 29 years) was used as a distinct category on this Web site and was not further defined.

\section{Illness Factors}

We examined the effects of depressive symptom severity (total CES-D score) on intent not to accept a diagnosis of depression. CES-D score was incorporated as a continuous variable adjusting for its non-log-linear relationship with the outcome variable. We reported results for CES-D scores using indicator variables for score quartiles for ease of interpretation and because the quartiles closely approximated the nonlinear relationship between the outcome variable and CES-D score. Participants were asked about the presence (yes/no) in the past 4 weeks of symptoms of panic disorder ("sudden anxiety, heart pounding, short of breath"), generalized anxiety disorder ("very anxious, nervous, or panicky"), and alcohol abuse ("drinking $>5$ drinks/day" and "drinking more than usual").

\section{Statistical Analysis}

As appropriate, we used Pearson $\chi^{2}$ or Fisher exact tests to compare our Internet sample with the primary care sample. In our Internet sample, we used a 2-step multi-

NA $=$ Not applicable
Table 1. Comparison of Sample Characteristics between the Internet Sample and Primary Care Sample

\begin{tabular}{|c|c|c|c|}
\hline Characteristics & $\begin{array}{c}\text { Study } \\
\text { (Internet) } \\
\text { Sample }\end{array}$ & $\begin{array}{l}\text { Primary Care Sample } \\
\text { Age } 18 \text { to } 29 \text { Years }\end{array}$ & $\begin{array}{c}P \text { Value } \\
\text { Comparison* }\end{array}$ \\
\hline Total Sample & $N=10,642$ & $N=351$ & \\
\hline \multicolumn{4}{|l|}{ Demographic factors } \\
\hline Sex,$\%$ & & & $\leq .001$ \\
\hline Female & 75.9 & 83.2 & \\
\hline Male & 24.2 & 16.8 & \\
\hline Ethnicity, \% & & & $\leq .001$ \\
\hline White & 78.3 & 59.5 & \\
\hline African-American & 4.9 & 9.2 & \\
\hline Asian-American & 6.9 & 3.5 & \\
\hline Latino/a & 5.7 & 21.2 & \\
\hline Native American & 1.0 & 5.1 & \\
\hline Pacific Islander & 0.4 & 1.6 & \\
\hline Other race & 3.6 & Not available & \\
\hline \multicolumn{4}{|l|}{ Education ( $\%$ in each category) } \\
\hline Less than high school & 19.1 & 12.3 & $\mathrm{NA}^{+}$ \\
\hline High school graduate & 26.0 & 32.3 & $\mathrm{NA}^{+}$ \\
\hline Some college & 16.9 & 38.3 & $\mathrm{NA}^{+}$ \\
\hline College graduate & 37.9 & 17.1 & $\mathrm{NA}^{\dagger}$ \\
\hline $\begin{array}{l}\text { Mean income household } \\
\text { income, } \$\end{array}$ & $15,700 *$ & $14,766.81$ & $\mathrm{NA}^{\dagger}$ \\
\hline \multicolumn{4}{|l|}{ Illness factors, \% } \\
\hline CES-D score > mean score & 34.8 & 31.1 & $\geq .05$ \\
\hline CES-D score $>16$ & 12.7 & 12.1 & $\geq .05$ \\
\hline CES-D score $>24$ & 87.3 & 87.9 & $\geq .05$ \\
\hline \multicolumn{4}{|l|}{$\begin{array}{l}\text { Symptoms of mental } \\
\text { disorders, \% }\end{array}$} \\
\hline Panic attack symptoms & 52.5 & Not available & $N A^{\ddagger}$ \\
\hline Generalized anxiety symptoms & 76.5 & Not available & $N A^{\ddagger}$ \\
\hline $\begin{array}{l}\text { Drinking more alcohol than } \\
\text { usual }\end{array}$ & 19.9 & Not available & $N A^{\ddagger}$ \\
\hline $\begin{array}{l}5 \text { or more drinks in } 1 \text { day in } \\
\text { last } 4 \text { weeks }\end{array}$ & 27.1 & Not available & $N A^{\ddagger}$ \\
\hline Treatment history, \% & & & $\leq .001$ \\
\hline Medications only & 12.9 & 3.8 & \\
\hline Counseling only & 8.4 & 26.6 & \\
\hline Both & 21.1 & 30.4 & \\
\hline Neither & 56.2 & 39.2 & \\
\hline \multicolumn{4}{|l|}{ Family history of depression } \\
\hline Present & 45.9 & Not available & $N A^{\ddagger}$ \\
\hline Absent & 53.4 & Not available & $\mathrm{NA}^{\ddagger}$ \\
\hline
\end{tabular}

* $P$ values for either the Pearson $\chi^{2}$ test or Fisher exact test, as appropriate.

+ No statistical comparison made between information derived from Zip code level data in the Internet sample and individual responses in the primary care sample, as group-level data cannot be compared with individual-level data. No statistical comparison made because of no available data.

variate logistic regression model to evaluate the relationship between the independent variables and intent not to accept a diagnosis of depression. ${ }^{49}$ In the first step, we screened all the independent variables in bivariate linear regression analyses for statistical significance. Those with $P$ values $<.05$ were advanced to the multivariate model. We evaluated possible interactions between past 


\begin{tabular}{|c|c|c|c|}
\hline Factors & $\begin{array}{l}\text { Percent in Sample } \\
(\mathrm{N}=10,962)\end{array}$ & Factors & $\begin{array}{l}\text { Percent in Sample } \\
(\mathrm{N}=10,962)\end{array}$ \\
\hline \multirow{2}{*}{\multicolumn{2}{|c|}{$\begin{array}{l}\text { Beliefs and attitudes toward treatment } \\
\text { behaviors }\end{array}$}} & \multicolumn{2}{|l|}{ Subjective social norms } \\
\hline & & \multicolumn{2}{|l|}{ Embarrassed if my friends knew } \\
\hline Biological changes in the brain cause depression & & Strongly disagree & 10.1 \\
\hline Strongly agree & 19.6 & Disagree & 24.7 \\
\hline Agree & 41.3 & Neither & 19.4 \\
\hline Neither & 31.4 & Agree & 27.6 \\
\hline Disagree & 5.9 & Strongly agree & 18.2 \\
\hline Strongly disagree & 1.8 & \multicolumn{2}{|l|}{ Employer should not know } \\
\hline Medications are effective & & Strongly disagree & 4.5 \\
\hline Strongly agree & 15.8 & Disagree & 11.1 \\
\hline Agree & 50.1 & Neither & 17.0 \\
\hline Neither & 26.5 & Agree & 35.1 \\
\hline Disagree & 5.4 & Strongly agree & 32.2 \\
\hline Strongly disagree & 2.2 & \multicolumn{2}{|l|}{ My family would be disappointed } \\
\hline Treatment preferences & & Strongly disagree & 18.6 \\
\hline Medications & 32.1 & Disagree & 29.3 \\
\hline No preference & 22.6 & Neither & 22.7 \\
\hline Counseling & 32.1 & Agree & 19.5 \\
\hline Medications are addictive & & Strongly agree & 9.9 \\
\hline Strongly disagree & 3.6 & & \\
\hline Disagree & 15.7 & & \\
\hline Neither & 49.8 & & \\
\hline Agree & 22.5 & & \\
\hline Strongly agree & 8.3 & & \\
\hline
\end{tabular}

behavior and beliefs and attitudes, social norms, and the outcome variable using tests of interaction and stratified analyses. We calculated the proportion of model variance explained by each group of factors and conducted sensitivity analyses and goodness of fit tests.
$67 \%$ believed that their employer should not know about their depression. Nearly one half the participants reported a family history of depression.

\section{External Factors}

External factors accounted for $16 \%$ of model variance (Figure 2). As shown in Table 3, in bivariate analyses,

\section{RESULTS}

\section{Study Population}

As displayed in Table 1, we compared our Internet sample with a probabilistic representative primary care sample. Our Internet sample had similar depressive symptom levels, whether measured by 2 different commonly accepted cutoff scores or by a mean score. With regard to treatment history, included as one of our internal factors (Figure 1), our Internet sample had a greater percentage of persons who never had any depression treatment, suggesting the possible importance of our design of using the anonymous Internet medium for depression screening. Our Internet sample differed by having lower percentages of minority groups. Also, as shown in Table 2, our Internet sample included a strong belief in a biological cause and medical treatment approach for depression. With regard to subjective social norms,
Figure 2. Percentage of theory of reasoned action model variance explained by model factors.

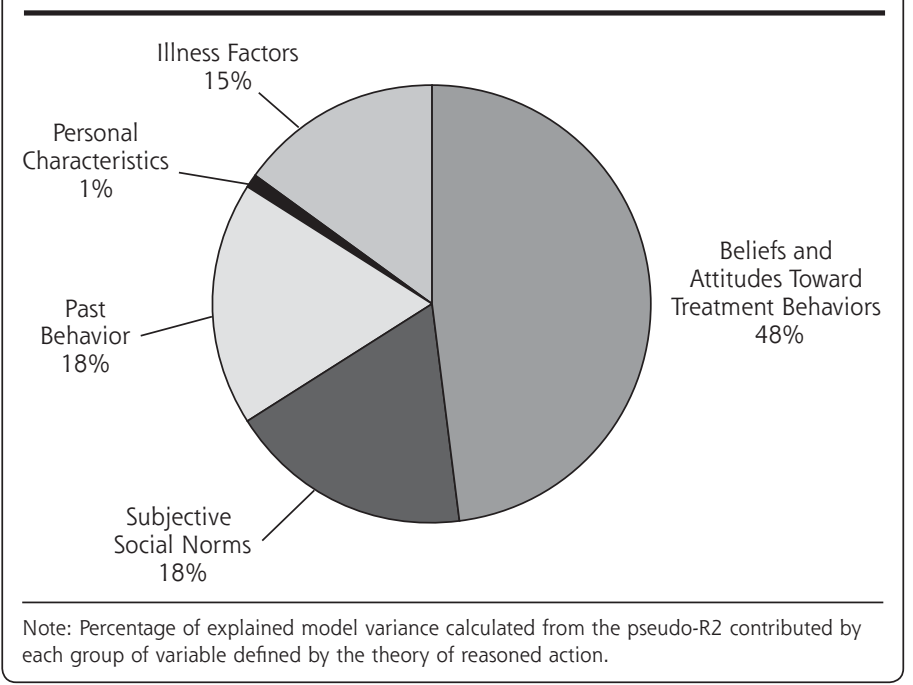




\begin{tabular}{|c|c|c|}
\hline \multirow[b]{2}{*}{ Factors } & \multicolumn{2}{|c|}{ Odds Ratio (95\% Cl) } \\
\hline & Unadjusted & Adjusted* \\
\hline \multicolumn{3}{|l|}{ Personal characteristics } \\
\hline \multicolumn{3}{|l|}{ Sex } \\
\hline Male & $1.13(1.02-1.25)^{\dagger}$ & $0.84(0.74-0.94)^{\ddagger}$ \\
\hline Female & 1.00 & 1.00 \\
\hline \multicolumn{3}{|l|}{ Ethnicity } \\
\hline White & 1.00 & 1.0 \\
\hline African-American & $1.22(0.99-1.48)$ & $0.89(0.72-1.12)$ \\
\hline Asian-American & $1.4(1.18-1.66)^{\S}$ & $0.85(0.69-1.04)$ \\
\hline Latino/a & $1.14(0.99-1.38)$ & $0.98(0.79-1.21)$ \\
\hline Native American & $1.02(0.66-1.66)$ & $0.99(0.60-1.66)$ \\
\hline Pacific Islander & $1.61(0.88-2.97)$ & $1.15(0.57-2.33)$ \\
\hline Other race & $1.13(0.89-1.43)$ & $0.98(0.75-1.27)$ \\
\hline \multicolumn{3}{|c|}{ Family history of depression } \\
\hline No & 1.00 & 1.00 \\
\hline Yes & $0.68(0.62-0.74)^{\S}$ & $0.92(0.83-1.03)$ \\
\hline \multicolumn{3}{|l|}{ Illness factors } \\
\hline \multicolumn{3}{|l|}{ CES-D score } \\
\hline 4th Quartile (43-60) & 1.00 & 1.00 \\
\hline 3rd Quartile (35-42) & $1.81(1.62-2.03)^{\S}$ & $1.27(1.09-1.48)^{\S}$ \\
\hline 2nd Quartile (28-34) & $3.58(3.18-4.03)^{\S}$ & $1.67(1.43-1.94)^{\S}$ \\
\hline 1st Quartile (17-27) & $8.18(7.24-9.25)^{\S}$ & $2.38(2.04-2.78)^{\S}$ \\
\hline \multicolumn{3}{|l|}{ Panic attack symptoms } \\
\hline No & 1.00 & 1.00 \\
\hline Yes & $0.83(0.76-0.91)^{\S}$ & $0.98(0.89-1.09)$ \\
\hline \multicolumn{3}{|c|}{ Generalized anxiety symptoms } \\
\hline No & 1.00 & 1.00 \\
\hline Yes & $0.71(0.64-0.78)^{\S}$ & $0.88(0.78-0.99)$ \\
\hline \multicolumn{3}{|l|}{$\mathrm{Cl}=$ confidence interval. } \\
\hline \multicolumn{3}{|c|}{$\begin{array}{l}\text { * Adjusted for all of the above, and beliefs and attitudes, social norms, and past treatment behavior } \\
\dagger P \leq .05 . \\
\text { † } P \leq .01 . \\
\S P \leq .001\end{array}$} \\
\hline
\end{tabular}

model, all the beliefs and attitudes, social norms, and past treatment behavior variables predicted the intent not to accept the diagnosis of depression. In the multivariate model, adjusting for a variety of variables including CES-D score, all remained predictive with the exception of the belief and attitude variable of "medications are addictive," the social norm variable of "employer should not know," the past treatment behavior variables of those who had received both medication and counseling treatment and rated one type as ineffective, and family history of depression. Those who strongly disagreed with the belief and attitude variable of "medications are effective" had odds ratios as high as 11.22. Removal of past treatment behavior variables from the model only minimally effected the relationship between the belief and attitude variables and intent. No interactions existed for belief and attitude, social norm, and past treatment behavior variables and intent.

\section{DISCUSSION}

Negative beliefs and attitudes and social norms, a variety of past treatment experiences, and low depressive symptom severity are the most important predictors of the intent not to accept a diagnosis of depression in young adults. Those with beliefs and attitudes of disagreeing with a biological approach to depression development and treatment are most likely to express intent not to accept a physician's diagnosis of depression.

male sex, Asian-American ethnicity, family history of depression, CES-D score, and presence of either generalized anxiety or panic symptoms predicted the intent not to accept the diagnosis of depression. In the multivariate analyses, only male sex and CES-D scores remained predictive, where the lower the depression level, the greater the intent not to accept the diagnosis of depression. The addition of past behavior (treatment) and family history of depression explained most of the loss of association in the multivariate model. The addition of social norms variables to the model explained the loss of association between no family history of depression and the outcome variable, from the bivariate to the multivariate model.

\section{Internal Factors}

Internal factors accounted for $84 \%$ of model variance (Figure 2). As displayed in Table 4, in the bivariate
This study uses an established behavioral theory to improve our understanding of the contribution of key beliefs and attitudes, subjective social norms, and past treatment behavior to help explain why certain young adults do not accept a depression diagnosis and are reluctant to obtain depression treatment. ${ }^{24,50-54}$ Our results of a preference for counseling resulting in a greater likelihood of not accepting a depression diagnosis may help explain why many primary care patients remain reluctant to accept counseling treatments. ${ }^{16}$ Behaviorally based treatment used in counseling may be less acceptable than biological treatment approaches. ${ }^{27,55} \mathrm{Also}$, the protective effect of a family history of depression for accepting a depression diagnosis may be related to the reduction of depression stigma by contact with affected family members. ${ }^{56,57}$

The principal limitations of this study in terms of 
internal validity are the lack of a close temporal relationship between expressing intent and performance, information on perceived behavioral control, current treatment status, and a confirmed diagnosis of depression. Although we do not know how participants would respond to a physician's diagnosis of depression, intent not to accept the diagnosis of depression was associated with not having obtained treatment for depression in the primary care sample. ${ }^{36,37}$ In developed countries, beliefs and attitudes toward treatment, rather than access to care, may be the critical determinants of mental health help-seeking behavior. ${ }^{14,58-60}$ In a previous study we found that adjustment for perceived behavioral control did not change the relationship between beliefs and attitudes and mental health help seeking in a primary care sample. ${ }^{16}$ Although we do not know which participants were currently seeking treatment, elimination of all those participants who reported previous treatment did not change the relationships between the internal factors and the intent variable. Although we do not know which participants met the criteria for a depressive disorder, we did adjust for that likelihood in our model by including the total CES-D score and symptoms of other mental disorders. We acknowledge that there could be certain additional beliefs and attitudes that may be relevant, too (eg, trust in providers, self-efficacy, self-esteem, and psychological mindedness).

With regard to external validity, our Internet participants had similar depressive symptom severity but contained higher proportions of whites and men than the comparison primary care sample. The Internet participants had less exposure to treatment than those in the primary care sample and most closely resembled those who did not seek treatment in the primary care sample. Such individuals are not often present in convenience clinic samples. Recruiting a sufficiently large number of symptomatic, untreated young adults to perform this multivariate analysis using probabilistic sampling methods would be difficult and prohibitively expensive.

These results have implications for general medical practice and health care policy. Our study suggests that behavioral theories can be used to develop models to understand and deconstruct the reasons why so few young adults seek and accept care for depression. Future studies should focus on understanding how physicians facilitate effective mental health care by focusing on

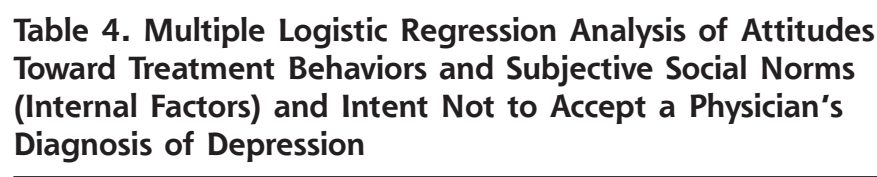

Table 4. Multiple Logistic Regression Analysis of Attitudes Toward Treatment Behaviors and Subjective Social Norms (Internal Factors) and Intent Not to Accept a Physician's Diagnosis of Depression

\begin{tabular}{|c|c|c|}
\hline \multirow[b]{2}{*}{ Factors } & \multicolumn{2}{|c|}{ Odds Ratio (95\% CI) } \\
\hline & Unadjusted & Adjusted* \\
\hline \multicolumn{3}{|c|}{$\begin{array}{l}\text { Beliefs and attitudes toward } \\
\text { treatment }\end{array}$} \\
\hline \multicolumn{3}{|c|}{$\begin{array}{l}\text { Biological changes in the brain } \\
\text { cause depression }\end{array}$} \\
\hline Strongly agree & 1.00 & 1.00 \\
\hline Agree & $1.55(1.36-1.78)^{5}$ & $1.22(1.04-1.43)^{\ddagger}$ \\
\hline Neither & $2.15(1.87-2.47)^{\S}$ & $1.35(1.15-1.59)^{\S}$ \\
\hline Disagree & $3.72(3.05-4.53)^{\S}$ & $1.99(1.58-2.49)^{\S}$ \\
\hline Strongly disagree & $4.54(3.34-6.18)^{\S}$ & $1.89(1.32-2.71)^{\dagger}$ \\
\hline \multicolumn{3}{|c|}{ Medications are effective } \\
\hline Strongly agree & 1.00 & 1.00 \\
\hline Agree & $2.38(2.01-2.84) \S$ & $1.78(1.46-2.17)^{\S}$ \\
\hline Neither & $5.34(4.47-6.38)^{5}$ & $3.69(3.00-4.56)^{\S}$ \\
\hline Disagree & $8.94(7.10-11.25)^{\S}$ & $5.29(4.06-6.92)^{\S}$ \\
\hline Strongly disagree & $11.22(8.26-15.23)^{\S}$ & $6.50(4.57-9.26)^{\S}$ \\
\hline \multicolumn{3}{|l|}{ Treatment preferences } \\
\hline Medications & 1.00 & 1.00 \\
\hline No Preference & $1.54(1.36-1.75)^{5}$ & $1.26(1.09-1.45)^{\S}$ \\
\hline Counseling & $1.83(1.65-2.04)^{\S}$ & $1.24(1.09-1.41)^{5}$ \\
\hline \multicolumn{3}{|c|}{ Medications are addictive } \\
\hline Strongly disagree & 1.0 & 1.0 \\
\hline Disagree & $0.94(0.71-1.25)$ & $0.78(0.55-1.09)$ \\
\hline Neither & $1.38(1.06-1.80)$ & $0.76(0.55-1.04)$ \\
\hline Agree & $1.99(1.52-2.60)^{5}$ & $0.98(0.71-1.36)$ \\
\hline Strongly agree & $2.13(1.59-2.85)^{\S}$ & $0.94(0.66-1.33)$ \\
\hline \multicolumn{3}{|c|}{ Subjective social norms } \\
\hline \multicolumn{3}{|c|}{ Embarrassed if my friends knew } \\
\hline Strongly disagree & 1.00 & 1.00 \\
\hline Disagree & $1.10(0.91-1.33)$ & $1.09(0.86-1.38)$ \\
\hline Neither & $1.73(1.43-2.09)^{5}$ & $1.52(1.20-1.93)^{\S}$ \\
\hline Agree & $2.07(1.73-2.48)^{5}$ & $1.71(1.36-2.17)^{\S}$ \\
\hline Strongly agree & $2.71(2.25-3.27)^{5}$ & $2.27(1.76-2.93)^{\S}$ \\
\hline \multicolumn{3}{|c|}{ Employer should not know } \\
\hline Strongly disagree & 1.00 & 1.00 \\
\hline Disagree & $1.09(0.83-1.46)$ & $1.17(0.83-1.66)$ \\
\hline Neither & $1.65(1.26-2.15)^{5}$ & $1.31(0.95-1.81)$ \\
\hline Agree & $1.76(1.36-2.26)^{5}$ & $1.26(0.92-1.74)$ \\
\hline Strongly agree & $2.03(1.58-2.62)^{\S}$ & $1.16(0.85-1.60)$ \\
\hline \multicolumn{3}{|c|}{ My family would be disappointed } \\
\hline Strongly disagree & 1.00 & 1.00 \\
\hline Disagree & $1.11(0.96-1.28)$ & $0.94(0.79-1.11)$ \\
\hline Neither & $1.79(1.55-2.07)^{5}$ & $1.42(1.19-1.68)^{\S}$ \\
\hline Agree & $1.85(1.59-2.14)^{\S}$ & $1.48(1.24-1.77)^{\S}$ \\
\hline \multirow[t]{2}{*}{ Strongly agree } & $2.48(2.09-2.94)^{\S}$ & $1.82(1.46-2.25)^{\S}$ \\
\hline & & continued on next page \\
\hline
\end{tabular}




\begin{tabular}{|c|c|c|}
\hline \multirow[b]{2}{*}{ Factors } & \multicolumn{2}{|c|}{ Odds Ratio (95\% Cl) } \\
\hline & Unadjusted & Adjusted* \\
\hline \multicolumn{3}{|l|}{ Past treatment behavior } \\
\hline \multicolumn{3}{|l|}{ Past treatment experience } \\
\hline No prior treatment & 1.00 & 1.00 \\
\hline Both treatments unhelpful & $0.66(0.54-0.81)^{\S}$ & $0.72(0.57-0.92)^{\ddagger}$ \\
\hline Medication Helpful & $0.43(0.37-0.51)^{\S}$ & $0.67(0.56-0.81)^{\S}$ \\
\hline Medication not helpful & $0.57(0.44-0.73)^{\S}$ & $0.63(0.48-0.84)^{\ddagger}$ \\
\hline Counseling helpful & $0.53(0.43-0.66)^{\S}$ & $0.58(0.46-0.74)^{\S}$ \\
\hline Counseling not helpful & $0.68(0.56-0.82)^{\S}$ & $0.81(0.66-1.00)^{\dagger}$ \\
\hline $\begin{array}{l}\text { Medication helpful/ counseling } \\
\text { not helpful }\end{array}$ & $0.41(0.32-0.53)^{\S}$ & $0.79(0.60-1.04)$ \\
\hline $\begin{array}{l}\text { Counseling helpful/ medication } \\
\text { not helpful }\end{array}$ & $0.58(0.43-0.78)^{\S}$ & $0.73(0.52-1.02)$ \\
\hline Both treatments helpful & $0.37(0.29-0.46)^{\S}$ & $0.67(0.52-0.85)^{\S}$ \\
\hline \multicolumn{3}{|l|}{ Family history of depression } \\
\hline No & 1.00 & 1.00 \\
\hline Yes & $0.68(0.62-0.75)^{\S}$ & $0.93(0.84-1.03)$ \\
\hline \multicolumn{3}{|l|}{$\mathrm{Cl}=$ confidence interval. } \\
\hline \multicolumn{3}{|c|}{$\begin{array}{l}\text { * Adjusted for all of the above and sex, age, ethnic group, treatment history, family history of } \\
\text { depression, CES-D score, anxiety symptoms, panic symptoms, alcohol abuse symptoms, attitudes and } \\
\text { social norms. } \\
\dagger P \leq .05 . \\
\ddagger P \leq .01 . \\
\text { § } P \leq .001 .\end{array}$} \\
\hline
\end{tabular}

3. Klerman $\mathrm{GL}$, Weissman MM. Increasing rates of depression. JAMA. 1989;261:2229-2235.

4. Reinherz HZ, Giaconia RM, Hauf AMC, Wasserman MS, Paradis AD. General and specific childhood risk factors for depression and drug disorders by early adulthood. J Am Acad Child Adolesc Psychiatry. 2000;39:223-231.

5. Horwitz AV, White HR. Becoming married, depression, and alcohol problems among young adults. Health Soc Behav. 1991;32:221-237.

6. Ernst C, Foldenyi M, Angst J. The Zurich Study: XXI. Sexual dysfunctions and disturbances in young adults. Data of a longitudinal epidemiological study. Eur Arch Psychiatry Clin Neurosci. 1993;243:179-188.

7. Binder ], Angst ]. [Social consequences of psychic disturbances in the population: a field study on young adults (author's transl)]. Arch Psychiatr Nervenkr. 1981;229:355-370.

8. Skodol AE, Schwartz S, Dohrenwend BP, Levav I, Shrout PE. Minor depression in a cohort of young adults in Israel. Arch Gen Psychiatry. 1994;51:542-551.

9. Runeson B. Mental disorder in youth suicide. DSM-III-R Axes I and II. Acta Psychiatr Scand. 1989;79:490-497.

10. Breslau N, Kilbey MM, Andreski P. DSM-III-R nicotine dependence in young adults: prevalence, correlates and associated psychiatric disorders. Addiction. 1994;89:743-754.

11. Christie KA, Burke JD, Regier DA, Rae DS, et al. Epidemiologic evidence for early onset of mental disorders and higher risk of drug abuse in young adults. Am J Psychiatry. 1988;145:971-975. specific patient concerns. Policy makers should consider improved reimbursement to primary care physicians for visits during which they negotiate diagnosis and treatment plans with depressed patients. Reimbursement would provide an incentive for these physicians to spend the time needed to diagnose and manage depression appropriately, which would likely increase patients' confidence in evidence-based treatments and their receipt of guideline-concordant depression care.

To read or post commentaries in response to this article, see it online at http://www.annfammed.org/cgi/content/full/3/1/38.

Key words: Depression/therapy; attitude; stereotyping; adolescent; young adult

Submitted December 16, 2003; submitted, revised, September 22, 2004; accepted October 20, 2004.

Funding support: This work was supported by NRSA grant T32PE10025

Acknowledgment: The assistance of Donica E. Van Voorhees, MTS, in reviewing this manuscript is gratefully acknowledged.

\section{References}

1. Kessler RC, Walters EE. Epidemiology of DSM-III-R major depression and minor depression among adolescents and young adults in the National Comorbidity Survey. Depress Anxiety. 1998;7:3-14.

2. Klerman GL. The current age of youthful melancholia. Evidence for increase in depression among adolescents and young adults. $\mathrm{Br}$ J Psychiatry. 1988;152:4-14.
12. Young AS, Klap R, Sherbourne CD, Wells KB. The quality of care for depressive and anxiety disorders in the United States. Arch Gen Psychiatry. 2001;58:55-61.

13. Druss BG, Hoff RA, Rosenheck RA. Underuse of antidepressants in major depression: prevalence and correlates in a national sample of young adults. J Clin Psychiatry. 2000;61:234-237.

14. Fortney J, Rost K, Zhang M. A joint choice model of the decision to seek depression treatment and choice of provider sector. Med Care. 1998;36:307-320.

15. Mechanic D. The epidemiology of illness behavior and its relationship to physical and psychological stress. In: Mechanic D, ed. Symptoms, Illness Behavior and Help Seeking. New York, NY: Neale Watson Academic Publications, Inc; 1982:1-24.

16. Van Voorhees BW, Cooper LA, Rost KM, et al. Primary care patients with depression are less accepting of treatment than those seen by mental health specialists. J Gen Intern Med. 2003;18:991-1000.

17. Williams JW Jr, Rost K, Dietrich AJ, Ciotti MC, Zyzanski SJ, Cornell J. Primary care physicians' approach to depressive disorders. Effects of physician specialty and practice structure. Arch Fam Med. 1999;8:58-67.

18. Lin E, Parikh SV. Sociodemographic, clinical, and attitudinal characteristics of the untreated depressed in Ontario. J Affect Disord. 1999;53:153-162.

19. Meadows G, Burgess P, Fossey E, Harvey C. Perceived need for mental health care, findings from the Australian National Survey of Mental Health and Well-being. Psychol Med. 2000;30:645-656.

20. Leaf PJ, Bruce ML, Tischler GL. The differential effect of attitudes on the use of mental health services. Soc Psychiatry. 1986;21:187-192.

21. Bultman DC, Svarstad BL. Effects of pharmacist monitoring on patient satisfaction with antidepressant medication therapy. J Am Pharm Assoc (Wash). 2002;42:36-43.

22. Thase ME. The roles of psychosocial factors and psychotherapy in refractory depression: missing pieces in the puzzle of treatment resistance? In: Nolen WA, Zohar J et al, eds. Refractory Depression: Current Strategies and Future Directions. New York, NY: John Wiley; 1994;83-95. 
23. Brown C, Schulberg HC, Prigerson HG. Factors associated with symptomatic improvement and recovery from major depression in primary care patients. Gen Hosp Psychiatry. 2000;22:242-250.

24. Mojtabai R, Olfson M, Mechanic D. Perceived need and help-seeking in adults with mood, anxiety, or substance use disorders. Arch Gen Psychiatry. 2002;59:77-84.

25. Carter WB. Health behavior as a rational process: theory of reasoned action and multiatribute utility theory. In: Glanz K, Lewis FML, Rimer BK, eds. Health Behavior and Health Education. San Francisco: JosseyBass; 1990:63-90.

26. Halgin RP, Weaver DD, Edell WS, Spencer PG. Relation of depression and help-seeking history to attitudes toward seeking professional psychological help. J Couns Psychol. 1987;34:177-185.

27. Howland MJ. Examining the decision to seek professional psychological help: A comparison of attribution and attitude theory in predicting helpseeking intention using the theory of reasoned action [dissertation]. University of Illinois at Urbana-Champaign; 1997.

28. Hagger MS, Chatzisarantis NL, Biddle, SJ. A meta-analytic review of the theories of reasoned action and planned behavior in physical activity: predictive validity and the contribution of additional variables. J Sport Exer Psychol. 2002; 24:3-3228.

29. Ajzen I. The directive influence of attitudes on behavior. Gollwitzer PM, Bargh JA, eds. The Psychology of Action: Linking Cognition and Motivation to Behavior. New York, NY: Guilford; 1996:385 403.

30. Lenert L, Skoczen S, Eysenbach G, Wyatt J. The Internet as a research tool: worth the price of admission? Using the internet for surveys and health research. Ann Behav Med. 2002;24:251-256.

31. Eysenbach G, Wyatt J. Using the internet for surveys and health research. J Med Internet Res. 2002;4:E13.

32. Hanauer D, Dibble E, Fortin J, Col NF. Internet use among community college students: implications in designing healthcare interventions. J Am Coll Health. 2004;52:197-202.

33. Borzekowski DL, Rickert VI. Adolescent cybersurfing for health information: a new resource that crosses barriers. Arch Pediatr Adolesc Med. 2001;155:813-817.

34. Gould MS, Munfakh JL, Lubell K, Kleinman M, Parker S. Seeking help from the internet during adolescence. J Am Acad Child Adolesc Psychiatry. 2002;41:1182-1189.

35. Skinner H, Biscope S, Poland B, Goldberg E. How adolescents use technology for health information: implications for health professionals from focus group studies. J Med Internet Res. 2003;5:e32.

36. Cooper LA, Gonzales JJ, Gallo JJ, et al. The acceptability of treatment for depression among African-American, Hispanic, and white primary care patients. Med Care. 2003;41:479-489.

37. Rost KM, Duan N, Rubenstein LV, et al. The Quality Improvement for Depression collaboration: general analytic strategies for a coordinated study of quality improvement in depression care. Gen Hosp Psychiatry. 2001;23:239-253.

38. Houston TK, Cooper LA, Vu HT, Kahn J, Toser J, Ford DE. Screening the public for depression through the Internet. Psychiatr Serv. 2001;52:362-367.

39. Radloff LS. The use of the Center for Epidemiologic Studies Depression Scale in adolescents and young adults. J Youth Adolesc. 1991;20:149-166.

40. Husani B, Neff J, Harrington J, Hughes M, Stone R. Depression in rural communities: validating the CES-D Scale. J Commun Psychol. 1980;8:137-146

41. Zich JM, Attkisson CC, Greenfield TK. Screening for depression in primary care clinics: the CES-D and the BDI. Int J Psychiatry Med. 1990;20:259-277.
42. Parikh RM, Eden DT, Price TR, Robinson RG. The sensitivity and specificity of the Center for Epidemiologic Studies Depression Scale in screening for post-stroke depression. Int J Psychiatry Med. 1988; 18:169-181.

43. Haringsma R, Engels GI, Beekman AT, Spinhoven P. The criterion validity of the Center for Epidemiological Studies Depression Scale (CES-D) in a sample of self-referred elders with depressive symptomatology. Int J Geriatr Psychiatry. 2004;19:558-563.

44. Beekman AT, Deeg DJ, Van Limbeek J, Braam AW, De Vries MZ, Van Tilburg W. Criterion validity of the Center for Epidemiologic Studies Depression scale (CES-D): results from a community-based sample of older subjects in the Netherlands. Psychol Med. 1997;27:231-235.

45. Radloff LS. The CES-D scale: a self-report depression scale for research in the general population. Applied Psychological Measures. $1977 ; 1: 385-401$

46. Eagly AH, Chaiken S. Attitude structure and function. In: Gilbert DT, Fiske ST, eds. The Handbook of Social Psychology, Vol. 1. 4th ed. New York, NY: McGraw-Hill; 1998:269-322.

47. Cooper-Patrick L, Powe NR, Jenckes MW, Gonzales JJ, Levine DM, Ford DE. Identification of patient attitudes and preferences regarding treatment of depression. J Gen Intern Med. 1997;12:431-438.

48. Cooper LA, Brown C, Vu HT, et al. Primary care patients' opinions regarding the importance of various aspects of care for depression. Gen Hosp Psychiatry. 2000;22:163-173.

49. STATA 7 Users Guide. Vol U. College Station, TX: STATA Press; 19852000.

50. Bultman DC, Svarstad BL. Effects of physician communication style on client medication beliefs and adherence with antidepressant treatment. Patient Educ Couns. 2000;40:173-185.

51. Loewenthal KM, Cinnirella M, Evdoka G, Murphy P. Faith conquers all? Beliefs about the role of religious factors in coping with depression among different cultural-religious groups in the UK. Br J Med Psychol. 2001;74:293-303.

52. Furnham A, Malik R. Cross-cultural beliefs about "depression." Int Soc Psychiatry. 1994;40:106-123.

53. Sirey JA, Meyers BS, Bruce ML, Alexopoulos GS, Perlick DA, Raue P. Predictors of antidepressant prescription and early use among depressed outpatients. Am J Psychiatry. 1999;156:690-696.

54. Jorm AF, Christensen H, Medway J, Korten AE, Jacomb PA, Rodgers B. Public belief systems about the helpfulness of interventions for depression: associations with history of depression and professional help-seeking. Soc Psychiatry Psychiatr Epidemiol. 2000;35:211-219.

55. Kuyken W, Brewin CR, Power MJ, Furnham A. Causal beliefs about depression in depressed patients, clinical psychologists and lay persons. Br J Med Psychol. 1992;65:257-268.

56. Corrigan PW, Penn DL. Lessons from social psychology on discrediting psychiatric stigma. Am Psychol. 1999;54:765-776.

57. Penn DL, Corrigan PW. The effects of stereotype suppression on psychiatric stigma. Schizophr Res. 2002;55:269-276.

58. Andrews G, Anstey K, Brodaty H, Issakidis C, Luscombe G. Recall of depressive episode 25 years previously. Psychol Med. 1999;29:787 791.

59. Kessler RC, Frank RG, Edlund M, Katz SJ, Lin E, Leaf P. Differences in the use of psychiatric outpatient services between the United States and Ontario. N Engl J Med. 1997:336:551-557.

60. Leaf PJ, Bruce ML, Tischler GL, Freeman DH, Jr., Weissman MM, Myers JK. Factors affecting the utilization of specialty and general medical mental health services. Med Care. 1988;26:9-26. 